\title{
Disparity in HPV Vaccine Use 2009-2015 among Young Adults in the US Interview Survey
}

\author{
Tang Ruyi \\ Grade 11, Indian Springs School \\ 1st 190 Woodward Drive I Indian Springs, AL \\ 001- 2052079570 \\ danatang@outlook.com
}

\begin{abstract}
Objectives: This study aimed to examine difference in HPV vaccine receipt proportion among recipients of different regions, races and genders using national data.

Methods: National Health Interview Survey (NHIS) data in year 2009, 2011, 2012, 2013, 2014 and year 2015 were used. All participants in this study were between 18 -26 years old as the last day of survey year. The outcomes of interest include 'ever received any HPV vaccine' and 'ever received three-dose HPV vaccine'. Logistic regression models were conducted to test if there is improvement in HPV immunization over the years compared to year 2009. We also examine the HPV immunization disparity due to sex, race, region, etc. The final weighting variable was applied for all the analysis in this study.
\end{abstract}

Results: A total of 1929 (17,969,653 after weighting) in year 2009, 4333 (36,946,340 after weighting) in year 2011, 4369 $(36,722,787$ after weighting) in year $2012,4225(36,221,482$ after weighting) in year 2013, 4277 (35,920,194 after weighting) in year 2014, $3674(35,063,591$ after weighting) in year 2015 were included in the final analysis. The average age was 22.0 in each year.

Approximately $19 \%$ of the participants in year 2009 (female only) received HPV vaccine; it gradually increased to $28 \%$ of all (both male and female) in year 2015. Over the years, it increased from $19 \%$ in year 2009 to $42 \%$ in year 2015 for the females. Meanwhile it increased from 2\% in year 2011 to $13 \%$ in year 2015 for the males. Over the years, it increased from $26 \%$ in year 2009 to $35 \%$ in year 2015 for the Northeast region. Meanwhile it increased from $20 \%$ in year 2009 to $26 \%$ in year 2015 for the Midwest region. It increased from $17 \%$ in year 2009 to $26 \%$ in year 2015 for the South region. It increased from $18 \%$ in year 2009 to $28 \%$ in year 2015 for the South region. Over the years, it increased from $21 \%$ in year 2009 to $28 \%$ in year 2015 for the white. Meanwhile it increased from 15\% in year 2009 to $27 \%$ in year 2015 for the black. It increased from

Permission to make digital or hard copies of all or part of this work for personal or classroom use is granted without fee provided that copies are not made or distributed for profit or commercial advantage and that copies bear this notice and the full citation on the first page. To copy otherwise, or republish, to post on servers or to redistribute to lists, requires prior specific permission and/or a fee. Request permissions from Permissions@ acm.org.

ICMHI 2017, May 20 - 22, 2017, Taichung City,Taiwan. Copyright is held by the owner/author(s). Publication rights licensed to ACM. ACM 978-1-4503-5224-6/17/05

DOI: http://dx.doi.org/10.1145/3107514.3107528
$12 \%$ in year 2009 to $27 \%$ in year 2015 for the Asian. It increased from $10 \%$ in year 2009 to $19 \%$ in year 2015 for the others. All the difference were statistically significnat (pvalues $<0.05$ ). Simiar results were observed for 3-dose HPV vaccine receipt. Losgitic regression confirmed the regional dispary, sexual disparity, and racial disparity in HPV vaccine receipt were significant.

Conclusions: In this study we found that HPV vaccine use increased over the time. However, sexual disparity, regional disparity and racial disparity in HPV vaccine use continuously existed over the years. Measures to improve the proportion as well as to eliminate disparity were still nearly needed.

\section{CCS Concepts}

-General and reference $\rightarrow$ General conference proceedings - General and reference $\rightarrow$ Reference works

\section{Keywords}

HPV Vaccine; Medicine; Disparity among vaccine receivers.

\section{INTRODUCTION}

About 79 million Americans, most in their late teens and early 20 s, are infected with human papillomavirus (HPV). Each year, about 14 million people become newly infected. According to CDC, each year in the United States, about 19,000 cancers caused by HPV occur in women, and cervical cancer is the most common. About 8,000 cancers caused by HPV occur each year in men in the United States, and throat cancers are the most common.

A new study looking at the prevalence of HPV infections in girls and women before and after the introduction of the HPV vaccine shows a significant reduction in vaccine-type HPV in U.S. teens. The study, published in The Journal of Infectious Diseases, reveals that since the vaccine was introduced in 2006, vaccinetype HPV prevalence decreased by 56 percent among female teenagers 14-19 years of age. Unfortunately, only one third of girls aged 13-17 have been fully vaccinated with HPV vaccine. Countries such as Rwanda have vaccinated more than 80 percent of their teen girls. Our low vaccination proportions represent 50,000 preventable tragedies - 50,000 girls alive today will develop cervical cancer over their lifetime that would have been prevented if we reach 80 percent vaccination proportions. For every year we delay in doing so, another 4,400 girls will develop cervical cancer in their lifetimes.

A very high proportion of girls need to receive the vaccine to have a significant level of herd immunity. To achieve this, Healthy People 2020, which is a program that provides 
objectives for improving the health of all Americans, adopted a goal of $80 \%$ coverage with 3 -doses of the HPV vaccine among 13-15 years old females by 2020. Unfortunately, in the US, there have been low levels of vaccination, particularly in the southern states where a high proportion of cervical cancer cases are expected to occur in 2014. Regional disparities in HPV vaccination have been observed in the South among 18-26 years old females compared to other regions of the US. Data from the National Immunization Survey Teen (NIS-Teen) has also indicated that 13-17 years old in the South have lower proportions of HPV vaccination.

Through these promising results, public health experts and clinicians look forward to more people getting vaccinated for HPV. Routine vaccination at the of age 11-12 for both boys and girls is recommended, but according to recent national immunization surveys, only about half of all girls in the U.S.and far fewer boys - received the first dose of HPV vaccine. A series of three shots is recommended over six months. HPV vaccination is also recommended for older teens and young adults who had not been vaccinated when they were younger.

This study aimed to examine time trend as well sexual disparity, regional disparity as well as racial disparity in HPV vaccine receipt proportion using national data.

\section{METHOD}

\subsection{Data}

The National Health Interview Survey (NHIS) in year 2009, 2011, 2012, 2013, 2014 and year 2015 (after policy change) were used to conduct a pre-post analysis. For year 2010, we did not have the HPV information among the study population of interest. NHIS is the principal source of information on the health of the civilian noninstitutionalized population of the United States and is one of the major data collection programs of the National Center for Health Statistics (NCHS), which is part of the Centers for Disease Control and Prevention (CDC).

The National Health Interview Survey is a cross-sectional household interview survey. Sampling and interviewing are continuous throughout each year. The sampling plan follows a multistage area probability design that permits the representative sampling of households and noninstitutional group quarters (e.g., college dormitories). The sampling plan is redesigned after every decennial census.

\subsection{Statistical Analysis}

All participants in this study were 18-26 years old as the last day of survey in the survey year. The outcomes of interest include 'ever received any HPV vaccine' and 'ever received three-dose HPV vaccine'. Logistic regression models were conducted to test if there is improvement in HPV immunization over the years compared to year 2009. We also examine the HPV immunization disparity due to sex, race, region, etc.

Logistic regressions were used to assess the likelihood to receive HPV immunization. Sex, race, and age were controlled for in the multivariable analysis. Logistic regression is a part of a category of statistical models called generalized linear models, and it allows one to predict a discrete outcome from a set of variables that may be continuous, discrete, dichotomous, or a combination of these. Typically, the dependent variable is dichotomous and the independent variables are either categorical or continuous.

In this analysis, we analyzed the results after applying the weighting variable created by National Health Interview Survey.
Participants were excluded from this study if they were aged younger than 18 or older than 26 years old. Also participants who had missing information regarding HPV, age, sex, region, and race were excluded from this study.

\section{RESULTS}

A total of 1929 (17,969,653 after weighting) in year 2009,4333 (36,946,340 after weighting) in year 2011, $4369(36,722,787$ after weighting) in year 2012, 4225 (36,221,482 after weighting) in year 2013, 4277 (35,920,194 after weighting) in year 2014, 3674 (35,063,591 after weighting) in year 2015 were included in the final analysis.

The average age was 22.0 in each year. About $16 \%$ were from northeast region, 24\% from Midwest, 36\% from south, and $24 \%$ from west region. Approximately $45 \%$ male and $54 \%$ female were in each year except in year 2009 there was no male participant.

Over the years, $77 \%$ participants were white, $15 \%$ were black, $5 \%$ Asian and $2 \%$ were other races. The average BMI was about 27 in year 2009. Roughly 53\% had normal/underweight BMI (BMI $<25$ ), only $2 \%$ under weight and they were grouped with normal weight because of the relatively small size; $25 \%$ over weight (BMI 25-29); and $21 \%$ obesity (BMI >=30).

Approximately $19 \%$ of the participants in year 2009 (female only) received HPV vaccine; it gradually increased to $28 \%$ of all (both male and female) in year 2015. We observed a slight decline in year 2011 compared to year 2009 because only females were interviewed for HPV vaccine information in year 2009. Starting from year 2011, both females and males were interviewed for this information.

As to the recommended three-dose HPV vaccine, only $10 \%$ in year 2009 received it, and the proportion increased to $13 \%$ in year 2015. The increase was very slow and did not change at all in year 2004 and 2015, indicating a further slowdown in uptake of HPV vaccine. (Figure 1)

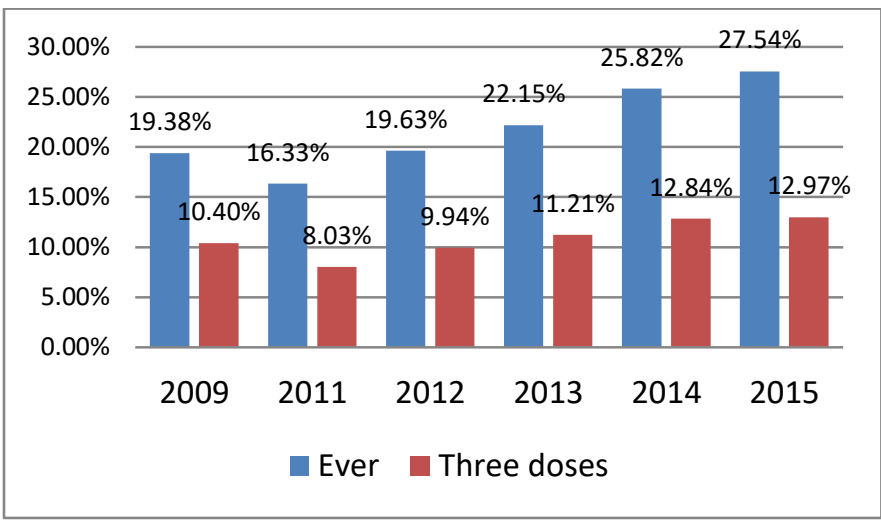

\section{Figure 1: Temporal trend of HPV Immunization among U.S. adults 18-26 years old}

Across each year, we observed a big difference in HPV vaccine receipt between males and females. In year 2009, only females were interviewed for HPV vaccine inforamtion. We had 19\% of the female ever had HPV vaccine and only $10 \%$ had 3-dose vaccine as recommened. In year 2011, 30\% of females had HPV vaccine versus $2 \%$ of males; while $16 \%$ had 3 -dose vaccine as recommened among the female versus $0.2 \%$ for the male. In year 2012, 36\% of females had HPV vaccine versus $4 \%$ of males; while $20 \%$ had 3 -dose vaccine as recommened among the females versus $1 \%$ for the males. In year 2013, $37 \%$ of females had HPV vaccine versus $8 \%$ of males; while $22 \%$ had 
3-dose vaccine as recommened among the females versus $1 \%$ for the males. In year 2014, $42 \%$ of females had HPV vaccine versus $10 \%$ of male; while $23 \%$ had 3 -dose vaccine as recommened among the females versus $3 \%$ for the males. In year $2015,42 \%$ of females had HPV vaccine versus $13 \%$ of male; while $23 \%$ had 3 -dose vaccine as recommened among the females versus $3 \%$ for the males.

Over the years, it increased from $19 \%$ in year 2009 to $42 \%$ in year 2015 for the females. Meanwhile it increased from 2\% in year 2011 to $13 \%$ in year 2015 for the males. As the 3-dose vaccine, it increased from $10 \%$ in year 2009 to $23 \%$ in year 2015 for the females; it increased from $0 \%$ in year 2011 to $3 \%$ in year 2015 for the males. Comapared with the females, the males were much less likely to receive HPV vaccine in each year, speciacly for the 3-dose HPV vaccine.

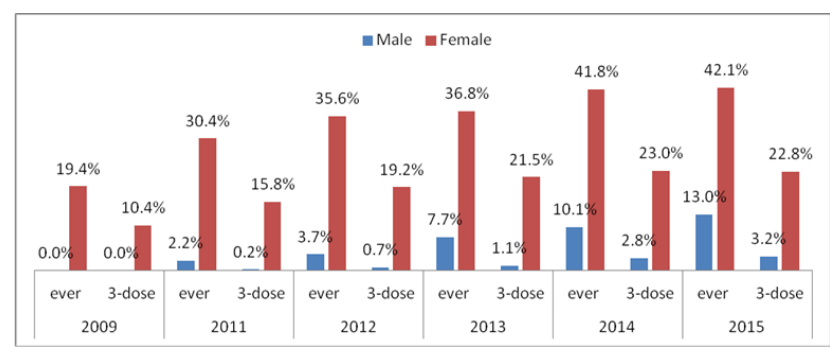

Figure 2: Sexual disparity in receipt of HPV vaccine among U.S. adults

Over the years, it increased from $26 \%$ in year 2009 to $35 \%$ in year 2015 for the Northeast region. Meanwhile it increased from $20 \%$ in year 2009 to $26 \%$ in year 2015 for the Midwest region. It increased from $17 \%$ in year 2009 to $26 \%$ in year 2015 for the South region. It increased from $18 \%$ in year 2009 to $28 \%$ in year 2015 for the South region. As of year 2015, Northeast region had the highest proportion of HPV vaccine receipt, and the rest three regions had a very similar proportion of HPV receipt. (Figure 3a)

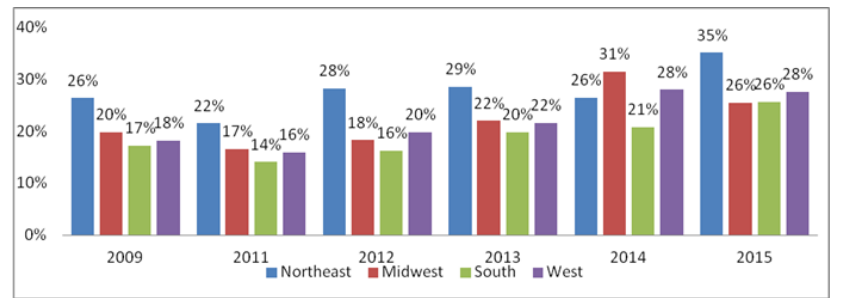

Figure 3a: Regional disparity in receipt of HPV vaccine among U.S. adults

As the 3-dose vaccine, it increased from $16 \%$ in year 2009 to $18 \%$ in year 2015 for the Northeast region. Meanwhile it increased from $10 \%$ in year 2009 to $11 \%$ in year 2015 for the Midwest region. It increased from $9 \%$ in year 2009 to $11 \%$ in year 2015 for the South region. It increased from $9 \%$ in year 2009 to $13 \%$ in year 2015 for the South region. As of year 2015, Northeast region had the highest proportion of 3-dose HPV vaccine receipt, and the rest three regions had a very similar proportion of 3-dose HPV receipt.

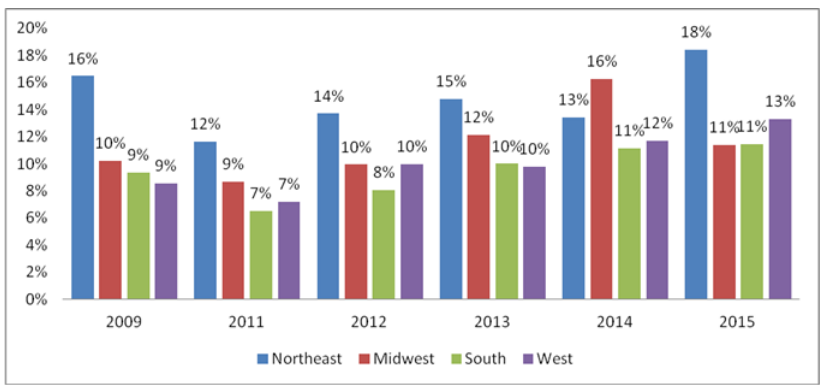

Figure 3b: Regional disparity in receipt of 3 dose of HPV vaccine among U.S. adults

Over the years, it increased from $21 \%$ in year 2009 to $28 \%$ in year 2015 for the white. Meanwhile it increased from $15 \%$ in year 2009 to $27 \%$ in year 2015 for the black. It increased from $12 \%$ in year 2009 to $27 \%$ in year 2015 for the Asian. It increased from $10 \%$ in year 2009 to $19 \%$ in year 2015 for the others. As of year 2015, the whites had the highest proportion of HPV vaccine receipt. (Figure 4a)

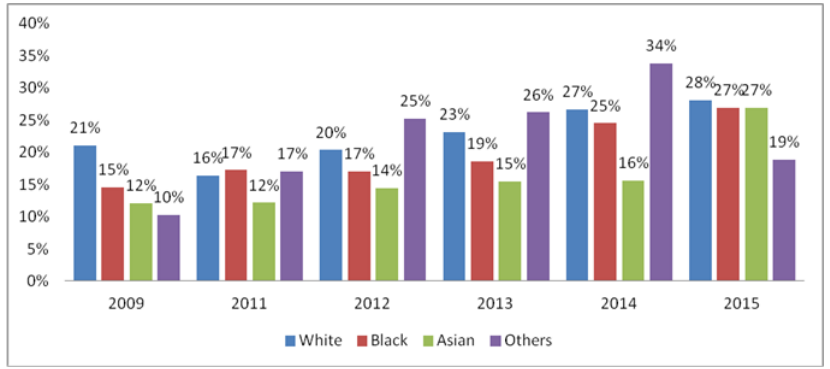

Figure 4a: Racial disparity in receipt of HPV vaccine among U.S. adults

As to the three-dose vaccine, it increased from $11 \%$ in year 2009 to $14 \%$ in year 2015 for the white. Meanwhile it increased from $5 \%$ in year 2009 to $9 \%$ in year 2015 for the black. It increased from $5 \%$ in year 2009 to $9 \%$ in year 2015 for the Asian. It increased from 5\% in year 2009 to $13 \%$ in year 2015 for the others. As of year 2015, the white had the highest proportion of HPV vaccine receipt, and followed by the other races, the black and the Asian. Over the years, it only increased 3\% points among the white, versus $4 \%$ points among the black, $4 \%$ points among the Asian and $8 \%$ points among the other races. (Figure $4 b)$

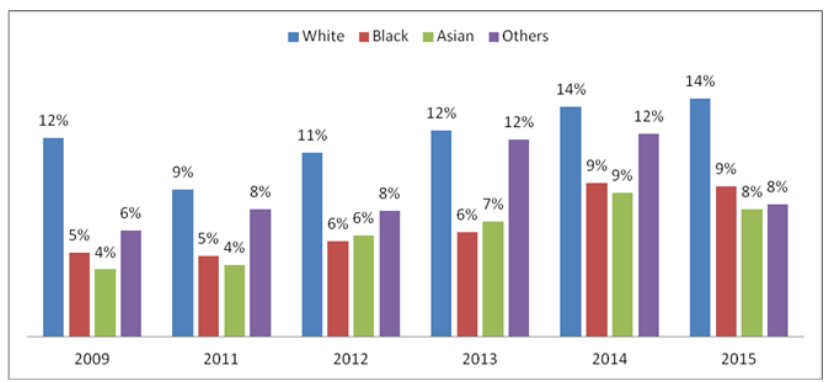

Figure 4b: Racial disparity in receipt of 3 dose of HPV vaccine among U.S. adults

According to logistic regressions, participants in year 2011 were 1.6 times $(\mathrm{OR}=1.623,95 \%$ CI: $1.621-1.625)$ more likely to receive any HPV vaccine, and 1.5 times $(\mathrm{OR}=1.536,95 \% \mathrm{CI}$ : 1.533-1.539) more likely to receive 3-dose HPV vaccine as recommended than those in year 2009. Participants in year 2012 were 2.1 times (OR=2.093, 95\% CI: 2.090-2.097) more 
likely to receive any HPV vaccine, and 2.0 times $(\mathrm{OR}=1.964,95 \%$ CI: 1.1.960-1.968) more likely to receive 3-dose HPV vaccine as recommended than those in year 2009. Participants in year 2013 were 2.6 times $(\mathrm{OR}=2.573,95 \% \mathrm{CI}: 2.570-2.577)$ more likely to receive any HPV vaccine, and 2.4 times $(\mathrm{OR}=2.345,95 \% \mathrm{CI}$ : 2.341-2.349) more likely to receive 3-dose HPV vaccine as recommended than those in year 2009. Participants in year 2014 were 3.3 times $(\mathrm{OR}=2.804,95 \% \mathrm{CI}$ : $2.799-2.809)$ more likely to receive any $\mathrm{HPV}$ vaccine, and 2.9 times $(\mathrm{OR}=2.908,95 \% \mathrm{CI}$ : $2.421-3.494)$ more likely to receive 3-dose HPV vaccine as recommended than those in year 2009. Participants in year 2015 were 3.7 times $(\mathrm{OR}=3.692$, 95\% CI: 3.686 -3.697) more likely to receive any HPV vaccine, and 2.872 times $(\mathrm{OR}=2.872,95 \%$ CI: $2.867-2.878$ ) more likely to receive 3 -dose HPV vaccine as recommended than those in year 2009.

Compared to participants in the Northeast, participants in the Midwest were less likley to receive HPV vaccine (OR $=0.704,95 \%$ CI: 0.703-0.705), and less likely (OR=0.709, 95\% CI: 0.708 $0.710)$ to receive 3 -dose HPV vaccine as recommended. Participants in the South were less likley to receive HPV vaccine (OR=0.552, 95\% CI: 0.552-0.553), and less likely ( $\mathrm{OR}=0.571$, 95\% CI: $0.570-0.572$ ) to receive 3 -dose HPV vaccine as recommended than those in the Northeast. Participants in the West were less likley to receive HPV vaccine (OR=0.731, 95\% CI: $0.730-0.732)$, and less likely $(\mathrm{OR}=0.640,95 \% \mathrm{CI}$ : 0.639 0.641 ) to receive 3 -dose HPV vaccine as recommended than those in the Northeast.

The males were much less likely to receive HPV vaccine $(\mathrm{OR}=0.119,95 \% \mathrm{CI}: 0.119-0.119)$, and less likely $(\mathrm{OR}=0.058$, 95\% CI: $0.058-0.058$ ) to receive 3 -dose HPV vaccine as recommended than than the females.

Compared to the white, the back were less likley to receive HPV vaccine ( $\mathrm{OR}=0.833,95 \% \mathrm{CI}: 0.832-0.834)$, and less likely $(\mathrm{OR}=0.493$, 95\% CI: $0.482-0.493)$ to receive 3-dose HPV vaccine as recommended. Asian participants were less likley to receive $\mathrm{HPV}$ vaccine $(\mathrm{OR}=0.638,95 \% \mathrm{CI}: 0.636-0.639)$, and less likely ( $\mathrm{OR}=0.489,95 \% \mathrm{CI}$ : $0.488-0.490)$ to receive 3 -dose HPV vaccine as recommended. Other race participants were less likley to receive HPV vaccine $(\mathrm{OR}=0.971,95 \% \mathrm{CI}$ : 0.969 $0.973)$, less likely $(\mathrm{OR}=0.736,95 \% \mathrm{CI}: 0.733-0.738)$ to receive 3-dose HPV vaccine as recommended.

People with obesity were less likely to receive HPV vaccine ( $\mathrm{OR}=0.832$, 95\% CI: 0.831-0.833), and less likely ( $\mathrm{OR}=0.883$, 95\% CI: 0.882-0.884) to receive 3-dose HPV vaccine as recommended than people with normal BMI. People with obesity as measrued by BMI were further less likely to receive HPV vaccine (OR=0.707, 95\% CI: 0.706-0.708), and less likely $(\mathrm{OR}=0.673$, 95\% CI: 0.672-0.674) to receive 3-dose HPV vaccine as recommended than people with normal BMI.

For people aged 18-26, the likelihood to receive HPV vaccine decreased by $13 \%$ as the age increased by 1 year $(\mathrm{OR}=0.866,95 \%$ CI: $0.865-0.866)$; the likelihood to receive 3 -dose HPV vaccine decreased by $10 \%$ as the age increased by 1 year $(\mathrm{OR}=0.898,95 \%$ CI: 0.898-0.898)

Table 1: Logistic regression result to model the receipt of HPV vaccine

\begin{tabular}{|l|l|l|l|l|l|l|}
\hline & \multicolumn{2}{|l|}{$\begin{array}{l}\text { Ever received HPV } \\
\text { vaccine }\end{array}$} & $\begin{array}{l}\text { Ever received 3-dose } \\
\text { HPV vaccine }\end{array}$ \\
\hline & OR & $\begin{array}{l}\text { Lowe } \\
\text { r CI }\end{array}$ & $\begin{array}{l}\text { Uppe } \\
\text { r CI }\end{array}$ & OR & $\begin{array}{l}\text { Lowe } \\
\text { r CI }\end{array}$ & $\begin{array}{l}\text { Uppe } \\
\text { r CI }\end{array}$ \\
\hline
\end{tabular}

\begin{tabular}{|c|c|c|c|c|c|c|}
\hline $\begin{array}{l}\text { Survey } \\
\text { year (2009 } \\
\text { as } \\
\text { reference) }\end{array}$ & & & & & & \\
\hline 2011 & $\begin{array}{l}1.62 \\
3\end{array}$ & 1.621 & 1.625 & $\begin{array}{l}1.53 \\
6\end{array}$ & 1.533 & 1.539 \\
\hline 2012 & $\begin{array}{l}2.09 \\
3\end{array}$ & 2.09 & 2.097 & $\begin{array}{l}1.96 \\
4\end{array}$ & 1.96 & 1.968 \\
\hline 2013 & $\begin{array}{l}2.57 \\
3\end{array}$ & 2.57 & 2.577 & $\begin{array}{l}2.34 \\
5\end{array}$ & 2.341 & 2.349 \\
\hline 2014 & $\begin{array}{l}3.28 \\
6\end{array}$ & 3.281 & 3.291 & $\begin{array}{l}2.80 \\
4\end{array}$ & 2.799 & 2.809 \\
\hline 2015 & $\begin{array}{l}3.69 \\
2\end{array}$ & 3.686 & 3.697 & $\begin{array}{l}2.87 \\
2\end{array}$ & 2.867 & 2.878 \\
\hline $\begin{array}{l}\text { Region } \\
\text { (Northeast } \\
\text { as } \\
\text { reference) }\end{array}$ & & & & & & \\
\hline Midwest & $\begin{array}{l}0.70 \\
4\end{array}$ & 0.703 & 0.705 & $\begin{array}{l}0.70 \\
9\end{array}$ & 0.708 & 0.71 \\
\hline South & $\begin{array}{l}0.55 \\
2\end{array}$ & 0.552 & 0.553 & $\begin{array}{l}0.57 \\
1\end{array}$ & 0.57 & 0.572 \\
\hline West & $\begin{array}{l}0.73 \\
1\end{array}$ & 0.73 & 0.732 & 0.64 & 0.639 & 0.641 \\
\hline $\begin{array}{l}\text { Sex } \\
\text { (female as } \\
\text { reference) }\end{array}$ & & & & & & \\
\hline Male & $\begin{array}{l}0.11 \\
9\end{array}$ & 0.119 & 0.119 & $\begin{array}{l}0.05 \\
8\end{array}$ & 0.058 & 0.058 \\
\hline $\begin{array}{l}\text { Race } \\
\text { (White as } \\
\text { reference) }\end{array}$ & & & & & & \\
\hline Black & $\begin{array}{l}0.83 \\
3\end{array}$ & 0.832 & 0.834 & $\begin{array}{l}0.49 \\
3\end{array}$ & 0.492 & 0.493 \\
\hline Asian & $\begin{array}{l}0.63 \\
8\end{array}$ & 0.636 & 0.639 & $\begin{array}{l}0.48 \\
9\end{array}$ & 0.488 & 0.49 \\
\hline Others & $\begin{array}{l}0.97 \\
1\end{array}$ & 0.969 & 0.973 & $\begin{array}{l}0.73 \\
6\end{array}$ & 0.733 & 0.738 \\
\hline \multicolumn{7}{|l|}{$\begin{array}{l}\text { BMI } \\
\text { (normal as } \\
\text { reference) }\end{array}$} \\
\hline $\begin{array}{l}\text { Overweigh } \\
\mathrm{t}\end{array}$ & $\begin{array}{l}0.83 \\
2\end{array}$ & 0.831 & 0.833 & $\begin{array}{l}0.88 \\
3\end{array}$ & 0.882 & 0.884 \\
\hline Obesity & $\begin{array}{l}0.70 \\
7\end{array}$ & 0.706 & 0.708 & $\begin{array}{l}0.67 \\
3\end{array}$ & 0.672 & 0.674 \\
\hline Age & $\begin{array}{l}0.86 \\
6\end{array}$ & 0.865 & 0.866 & $\begin{array}{l}0.89 \\
8\end{array}$ & 0.898 & 0.898 \\
\hline
\end{tabular}

\section{DISCUSSIONS}

This study demonstrated modest increases in proportions of receipt of HPV vaccine in 2015 among adults compared to year 2009. Nevertheless, only $43 \%$ of females received any HPV vaccine and $22 \%$ of females got 3 -dose as recommended in year 2015. Further improvement is needed to reduce HPV infection as well as cancer related to HPV. A new study looking at the prevalence of HPV infections in girls and women before and 
after the introduction of the HPV vaccine shows a significant reduction in vaccine-type HPV in U.S. teens. This information should be shared with broader audience to increase HPV awareness and the understanding of the benefits of HPV vaccine.

HPV vaccination is recommended by doctors and other health experts for boys at ages of 11 to 12 . HPV vaccination of boys is also likely to make benefits for girls by reducing the spread of HPV infection. However, in our study, we found that as of year 2015 , only $12 \%$ of the males received any HPV vaccine and only $3 \%$ received 3 -dose, compared to $43 \%$ and $22 \%$ of the females, respectively. The huge difference between two genders could be explained by the fact that many people think the HPV vaccine only protects girls, but this vaccine also prevents boys from certain HPV-related cancers. Thus, HPV should be understood better for both males and females. Every year, over 9,000 males are affected by cancers caused by HPV infections, which would stay with them for a long time. In a recent study, parents commonly raise 'health care provider didn't recommend it' and 'a lack of understanding about the vaccine' as reasons for not giving a HPV vaccine to their boys. Health education for parents as well as health care providers is needed to further improve the acceptance proportion among boys.

Regional disparity in HPV vaccine use continuously existed during our study year. Compared to Northeast, the other three regions were less likely to give HPV vaccine to their boys and girls.

In another study, girls in the South and Southwest were less likely to have initiated vaccination than those in the Northeast, Midwest and Western states. Regional disparity could be due to the difference in practice of providers in different regions.

In this study, we also found that as of year 2015, the other races had the highest proportion of HPV vaccine receipt, and followed by the black, white and Asian. Over the years, it only increased $10 \%$ points for the white, versus $14 \%$ points among the black, $11 \%$ points among the Asian and $23 \%$ points among the other races. However, after adjusting for other informaitn, e.g., gender, age, the balck, we found that Asian were still signifncantly less likely to receive HPV vaccine as well as 3-dose HPV vaccine, and the other races had a similar HPV vaccine proportion.

Another finding of this study is that although the HPV vaccine proportion increased a lot over the years, about half of the receipts did not get the 3-dose as recommended. As the 3-dose vaccine, the proportion increased from $9 \%$ in year 2009 to $22 \%$ in year 2015 for the females; it increased from $0 \%$ in year 2011 to $3 \%$ in year 2015 for the males. The Centers for Disease Control and Prevention called adherence proportions in the U.S. "unacceptably low," citing a report that showed only 38 percent of teen girls and 14 percent of teen boys finished the three-dose series. The adherence proportion for one dose was 57 percent for girls and 35 percent for boys. It is recommended that routine HPV vaccination should be initiated for females and males aged 11 or 12 . The vaccination series can be started as early as age 9 years old. Vaccination is also recommended for females aged 13 through 26 and for males aged 13 through 21 who have not been vaccinated previously or who have not completed the 3-dose series. All three HPV vaccines should be given as a 3-dose schedule, with the second dose given 1 to 2 months after the first dose and the third dose 6 months after the first dose. Very recently, US CDC recommended that 11- to 12-year-olds receive two doses of HPV vaccine at least six months apart rather than the previously recommended three doses to protect against cancers caused by human papillomavirus (HPV) infections. Teens and young adults who start the series later, at ages 15 through 26 years, will continue to need three doses of HPV vaccine to protect against cancer-causing HPV infection.

There were limitations in this study. Other variables which might have impacted HPV vaccine were not controlled in this study, for example, personal preference in vaccine and overall health status. However, we used BMI as a proxy of overall health status and controlled its potential effect.

In this study we found that HPV vaccine use increased over the time. However, sexual disparity, regional disparity and racial disparity in HPV vaccine use continuously existed over the years. Measures to improve the receipt as well as to eliminate disparity were still nearly needed.

\section{REFERENCE}

[1] Binghama, A., Janmohamed, A., An Approach to Formative Research in HPV Vaccine Introduction Planning in Low-Resource Settings, The Open Vaccine Journal, 2009, 2, 1-16

[2] In Proc Logistic Why Aren't The Coefficients Consistent With The Odds \& Ratios?, UCLA: Statistical Consulting Group., DOI = http://stats.idre.ucla.edu/sas/faq/in-proclogistic-why-arent-the-coefficients-consistent-with-theodds-ratios/

[3] What Are The Differences Between One-Tailed And TwoTailed Tests?, UCLA: Statistical Consulting Group., DOI = http://stats.idre.ucla.edu/other/mult-pkg/faq/general/faqwhat-are-the-differences-between-one-tailed-and-twotailed-tests/

[4] What Is Effect Coding?, UCLA: Statistical Consulting Group., DOI = http://stats.idre.ucla.edu/other/mult$\mathrm{pkg} / \mathrm{faq} /$ general/faqwhat-is-effect-coding/

[5] Hirth, J., Rahman, M., Smith, J., Regional variations in HPV vaccination among 9-17 year old adolescent females from the BRFSS, 2008-2010, Human Vaccines \& Immunotherapeutics, 2014

[6] Laz, T., Rahman, M., Berenson, A., Human papillomavirus vaccine uptake among 18-26 year old women in the United States: The National Health Interview Survey, 2010, US National Library of Medicine Institutes of Health, 2012

[7] Markowitz LE et al. Reduction in human papillomavirus (HPV) prevalence among young women following HPV vaccine introduction in the United States, National Health and Nutrition Examination Surveys, 2003-2010. J Infect Dis. 2013 Aug 1;208(3):385-93. doi: 10.1093/infdis/jit192. Epub 2013 Jun 19.

[8] World Health Organization . Human papillomavirus (HPV) and cervical cancer. DOI $=$ http://www.who.int/mediacentre/factsheets/fs380/en/ .

[9] CDC recommends only two HPV shots for younger adolescents. DOI = https://www.cdc.gov/media/releases/2016/p1020-hpvshots.html 